\title{
PROTEÇÃO DOS DIREITOS HUMANOS: CONSTITUCIONALIZAÇÃO DO DIREITO INTERNACIONAL OU INTERNACIONALIZAÇÃO DO DIREITO CONSTITUCIONAL?
}

\author{
Tatyana Scheila Friedrich ${ }^{1}$
}

\section{RESUMO}

Tanto o Direito Constitucional quanto o Direito Internacional sempre se preocuparam com o respeito aos Direitos Humanos. Todo o corpo jurídico que forma hoje o Direito Internacional dos Direitos Humanos teve inspiração em modelos constitucionais que lhes eram anteriores. É o que se pode observar no Pacto dos Direitos Civis e Políticos e no Pacto dos Direitos Econômicos, Sociais e Culturais. Com o desenvolvimento da proteção internacional e regional de tais direitos, atualmente verifica-se a influência do Direito Internacional sobre as Constituições locais, que surgem em conformidade, ou vão se adaptando, às novas regulamentações e exigências internacionais. A Constituição Brasileira caminha nesse sentido.

Indexadores: Direitos Humanos, Direito Internacional, Direito Constitucional

A Carta da ONU - Organização das Nações Unidas, de 1945, pode ser considerada como o primeiro instrumento internacional com preocupação explícita em relação ao tema da proteção geral dos direitos humanos. Antes dela, alguns textos internacionais já regulamentavam a temática, embora sob um aspecto específico, como a proteção da pessoa nas suas relações de trabalho, no tratado que deu origem à OIT - Organização Internacional do Trabalho; enquanto vítima de conflito armado, nos incipientes tratados de Direito Humanitário e da Guerra e como minoria, no Pacto que criou a Liga das Nações.

\footnotetext{
${ }^{1}$ Professora de Direito Internacional da Universidade Federal do Paraná

Revista Brasileira de Direito Internacional, Curitiba, v.8, n.8, jul/dez.2008
} 
A Declaração Universal, expedida pela Assembléia Geral da ONU, em 1948, tratou dos direitos humanos de forma mais aprofundada e abrangente que a Carta de São Francisco, com o mérito de aglutinar os direitos civis e políticos e também os direitos econômicos e sociais, numa concepção universalista e indivisível.

Para suprir a falta de juridicidade da Declaração, foram celebrados dois Tratados Internacionais de direitos humanos: 1) Pacto de Direitos Civis e Políticos, direcionados aos indivíduos, detentores dos direitos no texto previstos, e baseados no constitucionalismo que caracterizou o Estado Liberal no século XIX. 2) Pacto de Direitos Econômicos, Sociais e Culturais, baseados nas Constituições Sociais do século XX, como a do México (1917) e Weimar (1919), e direcionados aos Estados-partes, que se comprometem a fazer prestações positivas a fim de implementar tais direitos.

A distinção dos dois textos internacionais estava, na verdade, na concepção estatal que os fundamentava. De um lado, havia o modelo liberal que prevaleceu no período de surgimento e consolidação dos Estados Nacionais dos séculos XVII e XVIII, impondo a doutrina do "Laissez-faire, laissez-passer" e do "État Gendarme" - Estado Polícia, em que a atuação estatal é bastante reduzida e a ênfase é dada ao individualismo, em detrimento da sociedade. O modelo liberal estabelecia em sua concepção teórica que as próprias forças atuantes na sociedade realizariam os fins por ela determinados, com a intervenção do Estado apenas em caso de conflito. Na prática, os direitos eram assegurados pela formalização de sua declaração em norma jurídica, sendo que a constitucionalização dos direitos deu-se ao longo dos séculos XVIII e XIX.

As Constituições passaram a ter um papel fundamental pois tinham a função de limitar juridicamente o Estado e garantir as liberdades burguesas conquistadas com a decadência do sistema absolutista. $\mathrm{O}$ indivíduo era, nesse contexto, visto de forma restrita como um sujeito de direitos, que deveria pacificamente usufruir da independência que lhe é concedida.

O aparelho administrativo apareceu no Estado Liberal como um instrumento de racionalização do poder público e de impulsionamento do 
sistema capitalista, consubstanciado na fórmula da "Administração Pública Burocrática”, em que prevalecia a técnica, o procedimento, a estrutura e a legalidade.

A separação dos poderes, declarada nos textos constitucionais, encontrava no modelo liberal um campo de atuação absoluta, uma vez que ele prega o estado mínimo, limitado à tarefas legais: produção e execução da lei, e punição aos seus infratores.

Mas os próprios fundamentos do sistema - liberdade e igualdade ocasionaram a crise e decadência do Estado Liberal, conforme preceitua Carmen Lúcia ROCHA:

A liberdade comprometeu-se porque (...) não é livre quem não dispõe de condições mínimas, inclusive materiais (conquanto também políticas, psicológicas, espirituais, etc.), para assegurar-se a dignidade, que é própria de todo ser humano. E a igualdade jurídica falhou porque, ao contrário do que apregoava Rousseau em sua obra influente sobre os ideais revolucionários setecentistas, havia a possibilidade de alguém ser tão rico que poderia comprar o outro, tão miserável que tinha de se vender ao primeiro. Os direitos fundamentais formalmente reconhecidos ficaram onde se queria deixálos: na letra da lei sem força para se promoverem à ação vital da sociedade e do Estado.

O Estado Social, que se seguiu ao Estado Liberal, pretendeu superar exatamente esse limite de realização do humano que a convivência política requer e que a justifica: da idéia de Justiça Social ao ideal de Justiça Social, e desse ideal à concretização de condições políticas, econômicas e jurídicas que garantissem a "realização" dos direitos fundamentais havidos na base desse modelo de Estado. ${ }^{2}$

CLÈVE destaca ainda outros fatores justificadores da crise liberal e que impulsionaram a adoção de um modelo alternativo:

A crise recorrente do capitalismo, o sufrágio universal, as reivindicações da classe operária, as revoluções socialistas, a passagem da empresa individual para a coletiva e da concorrência para o oligopólio, a emergência da sociedade de massas e a conseqüente

\footnotetext{
${ }^{2}$ ROCHA, Cármen Lúcia Antunes. Princípios Constitucionais dos Servidores Públicos. São Paulo: Saraiva,1991. p. 16.
} 
urbanização pela qual passou o mundo, esses dados todos, somados a outros mais, concluíram por forçar o nascimento de um novo tipo de Estado. $^{3}$

Por outro lado, então, surge o Estado Social a partir da percepção de que os direitos fundamentais deveriam ser assegurados não apenas por escrito, mas através de promoção efetiva de ações sociais voltadas a sua concretização. Tais direitos, que no Estado liberal geravam apenas prestações estatais negativas, no Estado Social passaram a englobar também as prestações positivas - não basta mais o Estado apenas não interferir, de modo que o homem goze de sua liberdade, de seu direito a vida; agora ele tem que dar e fazer, como educação e saúde, por exemplo.

Para os estudiosos do papel do Estado, este não deveria mais ter atuação mínima na sociedade e na economia, mas precisaria passar a atuar como agente promotor e intervencionista, encarando o indivíduo não apenas como um sujeito de direitos mas como o beneficiário da efetivação de tais direitos.

Também denominado Estado do Bem-Estar ("Welfare State") e Estado de Serviços, suas bases estavam no Constitucionalismo Social que amadureceu no século XX: os direitos sociais ${ }^{4}$ são constitucionalizados; conceituados como direitos fundamentais; não-diferenciados dos direitos individuais; considerados como garantias sociais institucionais e geradores de prestações positivas dos Estados.

Sobre essa relação entre os direitos sociais e as Constituições, principalmente quanto aos temas constitucionais que se referem à ordem econômica e social, BONAVIDES escreve:

3 CLÈVE, Clemerson Merlin. Atividade Legislativa do Poder Executivo no Estado Contemporâneio e na Constituição de 1988. São Paulo: Editora Revista dos Tribunais, 1993. p. 38.

${ }^{4}$ ROCHA explica que, através de "alguns elementos retirados do direito comparado, poder-seia classificar os direitos sociais da seguinte maneira: a) direitos sociais à formação pessoal; b) direitos sociais à informação pessoal e social; c.1) direito de produzir; c.2) direito de aceder a serviços públicos essenciais; c.3) direito de consumir. Essa subclassificação poderia ser oferecida com o seguinte contorno: c.1) direito ao pão; c.2) direito de obter o pão; c.3) direito de consumir o pão; c.4) direito de transformar o pão; c.5) dever de repartir o pão com os demais membros da sociedade humana. ROCHA, Cármen Lúcia Antunes. Princípios Constitucionais dos Servidores Públicos. São Paulo: Saraiva,1991. p. 48.

Revista Brasileira de Direito Internacional, Curitiba, v.8, n.8, jul/dez.2008 
Assim como o Estado liberal foi a revolução da burguesia, e o Estado socialista, a revolução do proletariado, o Estado social é a terceira revolução da idade Moderna: a revolução da sociedade. Já não se trata portanto da revolução de uma classe, como vinha acontecendo em épocas políticas antecedentes, mas daquilo que poderá vir a ser talvez a última das revoluções: a revolução final pelo estabelecimento de um poder democrático legítimo. Com o movimento político de todas as classes, sela-se o pacto da convergência e solidariedade econômica e social, resultante de uma revolução sem sangue, nascida do consenso, da realidade e dos fatos, e assentada sobre um constitucionalismo social, que não precisa de dogmas, de teorias ou de frases; um constitucionalismo que se prende menos ao poder constituinte formal que aos poderes constituintes materiais. ${ }^{5}$

O Estado se comprometeu a atender o enorme rol dos direitos sociais, de forma democrática e participativa, aperfeiçoando a administração burocrática, a fim de atuar sistematicamente, sempre tendo em vista o interesse público e permitindo a fiscalização popular. Como o Estado Social era, antes de tudo, um executor ${ }^{6}$, a separação dos seus poderes mostrava-se debilitada, uma vez que havia uma demanda maior de atividades do Poder Executivo.

A crise do Estado Social passou a ser vista como decorrente do sistema excessivamente oneroso que é necessário manter para atender a todas as demandas sociais a que o Estado se comprometeu. Dessa forma, a população, que cria grande expectativa em relação aos serviços públicos prometidos, ficava desassistida ou recebia atendimentos sem qualidade. Também se alegou que o sistema não se manteve, principalmente nos países em desenvolvimento, devido a elementos que estão intrinsecamente ligados à sua concepção, tais como, inflação, endividamento externo e asfixia da economia privada pelo excesso de intervencionismo estatal.

Foram esses modelos liberal e social de Estado que pautaram a regulamentação dos Direitos Humanos como tema geral, através da elaboração dos Pactos. As Constituições que embasaram um ou outro tipo de Estado foram também referência para cada um dos Pactos, num processo de internacionalização do direito constitucional.

\footnotetext{
${ }^{5}$ BONAVIDES, Paulo. Teoria do Estado. São Paulo: Malheiros Editores, 3ed. p.232

${ }^{6} \mathrm{O}$ Estado Social também é comumente referido como Estado de Serviços ou Estado de Prestações
}

Revista Brasileira de Direito Internacional, Curitiba, v.8, n.8, jul/dez.2008 
Além dessa normativa não-específica, também a ONU organizou e estimulou a celebração de diversas convenções internacionais temáticas, como a Convenção para eliminação de todas as formas de discriminação racial, a Convenção para eliminação de todas as formas de tortura, tratamentos cruéis ou degradantes, Convenção sobre os Direitos da Mulher, Convenção sobre os Direitos das Crianças, dentre outras. Tais convenções criaram Comitês, responsáveis pelo monitoramento e acompanhamento do cumprimento de suas disposições pelos Estados signatários.

Paralelamente a esses mecanismos convencionais, por resolução de órgãos da ONU, foram criados outros instrumentos de controle da atuação dos Estados, quanto à promoção e proteção dos direitos humanos. Assim, surgiram os Grupos de Trabalho e, principalmente, o instituto dos Relatores Especiais, dentre os quais estão o relator especial sobre dejetos tóxicos; o relator especial sobre o direito à liberdade de opinião e expressão, sobre a questão da violência contra a mulher; sobre a questão da tortura; sobre execuções extrajudiciais, sumárias e arbitrárias. A partir de informações que recebem, esses agentes da ONU fazem investigações sobre a situação dos Estados, podendo, inclusive atuar in loco, como fizeram os relatores sobre a tortura e sobre execuções sumárias, que estiveram no Brasil em 2001 e 2003, respectivamente.

No que tange os mecanismos regionais de proteção dos direitos humanos, a Europa apresenta o sistema mais avançado, no qual os indivíduos, depois de esgotarem os recursos internos, têm acesso direto à Corte Européia de Direitos Humanos.

O sistema interamericano de direitos humanos faz parte da Organização dos Estados Americanos - OEA e tem como marcos jurídicos a Declaração Americana de Direitos Humanos, a Convenção Americana de Direitos Humanos, além de uma série de tratados sobre temas específicos, como direitos da mulher, tortura, discriminações, etc.. Ele é composto pela Comissão Interamericana de Direitos Humanos, que analisa denúncias de violações de direitos por parte dos Estados membros, e a Corte Interamericana de Direitos Humanos, que julga casos trazidos pela Comissão, contra Estados 
que reconheceram expressamente sua jurisdição. Apesar das críticas da doutrina especializada, o indivíduo ainda não tem o direito de petição perante a Corte, cujos casos passam antes pelo crivo da Comissão.

A África, a Ásia e os países islâmicos ainda possuem mecanismos muito incipientes de proteção de direitos humanos. De qualquer forma, todas as iniciativas aqui relatadas demonstram ser instrumentos para a necessária conscientização mundial de que "reconhecimento da dignidade inerente a todos os membros da família humana e de seus direitos iguais e inalienáveis é o fundamento da liberdade, da justiça e da paz no mundo". ${ }^{7}$

O Brasil está vinculado ao sistema interamericano, ao qual foi aderindo concomitantemente ao seu processo de democratização. A Constituição Brasileira de 1988 teve seu artigo 5․ inspirado em vários dos textos internacionais de proteção de Direitos Humanos aqui mencionados, num processo inverso de constitucionalização do direito internacional. A Emenda Constitucional $45^{8}$ reforçou nossa tese, conforme as modificações realizadas no texto constitucional e que são expostas na seqüência:

1. Ao artigo 50, referente aos direitos fundamentais, foram acrescentados dois novos parágrafos. O parágrafo terceiro foi incorporado com a seguinte redação:

$\S 3^{\circ}$ Os tratados e convenções internacionais sobre direitos humanos que forem aprovados, em cada Casa do Congresso Nacional, em dois turnos, por três quintos dos votos dos respectivos membros, serão equivalentes às emendas constitucionais.

O texto original da Constituição Brasileira já fazia a previsão dos direitos fundamentais decorrentes de Tratados Internacionais através da redação do parágrafo $2^{\circ}$ do artigo quinto que, após elencar no caput $\mathrm{o}$ rol de direitos $\mathrm{e}$ deveres individuais e coletivos, prevê:

$\S 2^{\circ}$ Os direitos e garantias expressos nesta Constituição não excluem outros decorrentes do regime e dos princípios por ela adotados, ou dos

\footnotetext{
${ }^{7}$ Preâmbulo da Declaração Universal dos Direitos Humanos.

${ }^{8}$ Publicada no Diário Oficial da União no dia 31/12/2004, entrou em vigor em 1ํ. de janeiro de 2005, alterando dispositivos dos artigos 5ำ 36, 52, 92, 93, 95, 98, 99, 102, 103, 104, 105, 107 , 109,111 e 112.
}

Revista Brasileira de Direito Internacional, Curitiba, v.8, n.8, jul/dez.2008 
tratados internacionais em que a República Federativa do Brasil seja parte.

A inclusão do parágrafo $3^{\circ}$ parece ter ocorrido para superar a contínua divergência entre a doutrina e a jurisprudência, no que tange ao tema da hierarquia dos tratados internacionais de direitos humanos no ordenamento jurídico brasileiro.

A doutrina especializada sempre advogou a tese de que o texto do parágrafo $2^{\circ}$ indica o status constitucional de todos os tratados de direitos humanos ratificados pelo Brasil. O caráter progressista e emancipador da Constituição permite tal compreensão.

Ao efetuar tal incorporação, a carta está a atribuir aos direitos internacionais uma hierarquia especial e diferenciada, qual seja, a hierarquia de norma constitucional. Os direitos enunciados nos tratados de direitos humanos de que o Brasil é parte integram, portanto, o elenco dos direitos constitucionalmente consagrados. Esta conclusão advém ainda de interpretação sistemática e teleológica do texto, especialmente em face da força expansiva dos valores da dignidade humana e dos direitos fundamentais como parâmetros axiológicos a orientar a compreensão do fenômeno constitucional. ${ }^{9}$

Tal entendimento justifica-se a partir da análise de todo o artigo quinto da constituição, desde seu caput, passando por seus incisos até chegar aos seus parágrafos. A interpretação sistemática das cláusulas pétreas do artigo original reforça a tese do caráter constitucional das normas de direitos humanos decorrentes de tratados.

Em síntese, relativamente aos tratados internacionais de proteção dos direitos humanos, a Constituição brasileira de 1988, nos termos do art. $5^{\circ}$, parágrafo $1^{\circ}$, acolhe a sistemática da incorporação automática dos tratados, o que reflete a adoção da concepção monista. Ademais, (...) a Carta de 1988 confere aos tratados de direitos humanos o status de norma constitucional, por força do art. $5^{\circ}$, parágrafo $2^{\circ}$. O regime jurídico diferenciado conferido aos tratados de direitos humanos não é, todavia, aplicável aos demais tratados, isto é, aos tratados tradicionais. ${ }^{10}$

\footnotetext{
${ }^{9}$ PIOVESAN, Flavia. Direitos humanos e o Direito Constitucional Internacional. São Paulo: Max Limonad, 2000. 4.ed. p. 73-74.

${ }^{10}$ PIOVESAN, Flavia. Direitos humanos e o Direito Constitucional Internacional. São Paulo: Max Limonad, 2000. 4.ed. p. 101.
}

Revista Brasileira de Direito Internacional, Curitiba, v.8, n.8, jul/dez.2008 
CANÇADO TRINDADE explica que a proteção dos direitos humanos representa um interesse superior compartilhado pelos Estados da comunidade internacional, exigindo uma interação dos âmbitos internos e internacionais, quer em relação aos textos legislativos, quer em relação aos mecanismos e instrumentos de proteção.

Cabe, pois, naturalmente aos tribunais internos interpretar e aplicar as leis dos países respectivos, exercendo os órgãos internacionais especificamente a função de supervisão, nos termos e parâmetros dos mandatos que lhes foram atribuídos pelos tratados e instrumentos de direitos humanos respectivos. Mas cabe, ademais, aos tribunais internos, e outros órgãos dos Estado, assegurar a implementação a nível nacional das normas internacionais de proteção, o que realça a importância de seu papel em um sistema integrado como o da proteção dos direitos humanos, no qual as obrigações convencionais abrigam um interesse comum superior de todos os Estados Partes, o da proteção do ser humano. (...) Com efeito, graças à atuação - desde seus primórdios - dos órgãos de supervisão próprios aos sistemas europeu e interamericano de direitos humanos, em numerosos casos tem-se logrado pôr fim a práticas administrativas violatórias dos direitos humanos e alterar medidas legislativas para salvaguardar os direitos humanos. ${ }^{11}$

A jurisprudência brasileira relutou durante 20 anos para absorver tal entendimento doutrinário, insistindo no caráter de legislação ordinária dos tratados internacionais, seja em matéria de direitos humanos, seja em qualquer outro assunto. Os tribunais sempre foram questionados sobre o assunto ao se discutir o tema da prisão civil, admitida na Convenção Interamericana de Direitos Humanos (Pacto de São José da Costa Rica) apenas para o devedor de alimentos (art. $7^{\circ}, 7$ ) enquanto a Constituição Brasileira a prevê também para o depositário infiel (art. 5ํ, LXVII).

Felizmente, no dia 3 de dezembro de 2008, o Supremo Tribunal Federal estendeu a proibição de prisão civil por dívida à hipótese de infidelidade no depósito de bens e, por analogia, também à alienação fiduciária, revogando a Súmula 619/STF ("A prisão do depositário judicial pode ser

\footnotetext{
${ }^{11}$ TRINDADE, Antonio Augusto Cançado. (Ed) A Incorporação das Normas Internacionais de Proteção dos Direitos Humanos no Direito Brasileiro. San Jose, Costa Rica: Co-edição: IIDH, ACNUR, CICV, CUE, 1996. 216-217.
}

Revista Brasileira de Direito Internacional, Curitiba, v.8, n.8, jul/dez.2008 
decretada no próprio processo em que se constituiu o encargo, independentemente da propositura de ação de depósito").

A jurisprudência finalmente assumiu a visão doutrinária de que as normas dos Tratados Internacionais de Direitos Humanos devem ter autoridade de norma constitucional e, em caso de divergência, prevaleça a norma mais favorável ao indivíduo - o destinatário de todos este arcabouço jurídico.

A normativa internacional deve conviver com a interna tendo em vista que a proteção dos seres humanos ultrapassa os limites das fronteiras dos Estados porque tem por objetivo a busca do respeito da dignidade das pessoas, não como nacionais de determinado país, mas como fator mais importante de qualquer organização social e como razão de ser de qualquer regulamentação pelo Direito.

Foi nesse sentido, com aspecto complementar à atuação interna dos Estados, que se criou aquela sistemática supranacional de proteção dos direitos humanos, que envolve não apenas os mecanismos universais, organizados pela ONU, mas também os mecanismos regionais, sobretudo no âmbito da Europa e das Américas.

A alteração na Constituição e na jurisprudência brasileiras vem apenas reafirmar o status constitucional dos direitos humanos decorrentes de Tratados. No entanto, agora o Congresso Nacional deverá atentar para o quorum especial de 3/5 dos membros a fim de evitar a desvalorização do potencial daqueles acordos internacionais. Em nossa opinião, deverá realizar essa tarefa imediatamente, inclusive no que diz respeito aos tratados já ratificados.

2. O quarto parágrafo do artigo $5^{\circ}$ passou a vigorar com a seguinte redação:

$\S 4^{\circ} \mathrm{O}$ Brasil se submete à jurisdição de Tribunal Penal Internacional a cuja criação tenha manifestado adesão."

O "Estatuto de Roma", tratado internacional que criou o Tribunal Penal Internacional (TPI), foi assinado em 1988 em Roma e entrou em vigor no dia 
$1^{\circ}$. de julho de 2002, após do sexagésimo depósito de instrumento de ratificação. Foi um marco na história do direito internacional pois pela primeira vez se estabeleceu uma corte judicial internacional para julgar criminosos de guerra e perpetradores de genocídio e crimes contra a humanidade, quando não forem julgados por seus tribunais nacionais. Finalmente 0 mundo se mostrou pronto para criar um tribunal de caráter permanente e se livrar dos tribunais de exceção, criados pelos vencedores nos períodos posteriores às guerras ou pelo Conselho de Segurança da ONU para julgar situações localizadas.

O Brasil ratificou o Tratado de Roma, realizando o depósito do instrumento de ratificação no dia 20 de junho de 2002. Durante o processo de internalização do tratado, muito se questionou a respeito da constitucionalidade do artigo que trata do encaminhamento do cidadão brasileiro ao TPI, chegando alguns autores a entendê-lo como caso de extradição nacional, vetada pela própria Constituição Federal. Trata-se, em verdade, de mera entrega do nacional tendo em vista que ele será enviado para julgamento em um Tribunal Internacional, ao qual o Brasil aderiu. Não haverá extradição do nacional para ser julgado por corte de país estrangeiro, como requer o conceito.

Outra discussão importante ocorreu em torno do dispositivo que prevê a pena de prisão perpétua dentre aquelas que poderão ser aplicadas pelo Tribunal aos seus condenados. O entendimento adotado perpassou pela identificação da proibição da prisão perpétua do artigo $5^{\circ}$ como uma restrição nacional, uma garantida ao cidadão de que o juiz pátrio nunca irá infligir-lhe pena de prisão perpétua - ainda que seja permitido que, na comutação da pena, esta ultrapasse a idade que o condenado poderá viver.

O Brasil parecia ter resolvido sua relação com o TPI, adotando-o enquanto anseio da comunidade internacional e, através dele, propugnando pelo fim da impunidade aos grandes violadores de direitos humanos. Isso já estava reforçado pelo art. $7^{\circ}$ do Ato das Disposições Constitucionais Transitórias, que estabelece: "O Brasil propugnará pela formação de um tribunal internacional dos direitos humanos." A emenda 45 apenas confirmou essa situação, evitando quaisquer questionamentos futuros. 
O TPI foi instaurado em agosto de 2003, na cidade da Haia, mantendose, assim, a forte tradição da Holanda em matéria de Direito Internacional. Atualmente, mais de cem países já ratificaram o Tratado de Roma, o que tem gerado um ambiente de otimismo entre os teóricos e os militantes na área de direitos humanos. Mas ainda há muito a ser feito tendo em vista que poucos Estados elaboraram legislação doméstica para regulamentar a implementação interna do estatuto do TPI.

Durante seus primeiros anos de existência, as ações do TPI se concentraram na sua estruturação e na regulamentação de suas próprias atividades. Foram definidos o orçamento, as regras sobre procedimento e provas, os princípios determinantes para o acordo de sede com os Países Baixos e o acordo sobre privilégios e imunidades.

Além disso, foram escolhidos os 18 juízes $^{12}$ que compõem o quadro julgador, o argentino Moreno Ocampo como promotor e o francês Bruno Cathala para exercer as funções de escrivão. No dia 15 de março de 2005, o TPI iniciou sua primeira atividade juridicional, através da realização de uma audiência preliminar, a portas fechadas, sobre a investigação dos crimes de guerra cometidos na República Democrática do Congo - RDC. Trata-se do procedimento regular na fase de investigação dos fatos, em que se procede a uma consulta entre os juízes e a Procuradoria sobre a proteção das testemunhas e das vítimas, além do tema do sigilo de documentos. Paralelamente estão sendo estudados os crimes de guerra e crimes contra a humanidade perpetrados em Uganda, República Centro-Africana e Sudão (Darfur).

Em se tratando dos demais países, destaca-se a ausência de importantes atores do cenário internacional, como os Estados Unidos, Rússia, China e os Estados árabes. Dentre estes, a grande maioria chegou a assinar o Tratado mas apenas a Jordânia o ratificou.

\footnotetext{
${ }^{12}$ A composição do tribunal foi realizada da seguinte maneira: 18 juízes (incluindo a brasileira Dra. Sylvia Steiner), dentre os 43 indicados pelos Estados. Dos 43, 10 eram mulheres e 33 eram homens, sendo, do total, 8 vindos da América Latina e Caribe, 10 da África, 6 da Ásia, 12 da Europa Ocidental e 7 do Leste Europeu.
}

Revista Brasileira de Direito Internacional, Curitiba, v.8, n.8, jul/dez.2008 
Os EUA, sobretudo no governo Bush, têm se mostrado como os grandes opositores ao TPI. Chegaram a assinar o Estatuto de Roma em 31 de dezembro de 2000, no final do mandato de Bill Clinton, mas retrocederam ao retirar tal assinatura em 6 de maio de 2002. Além das inúmeras manifestações expressas contrárias à ratificação do tratado, o governo americano está forçando países a assinarem acordos bilaterais prevendo imunidade para cidadãos americanos ${ }^{13}$ (mais de 50 países já fizeram tais acordos). Internamente, o Congresso Norte-americano está editando uma ampla legislação visando a proteger e evitar que membros das Forças Armadas sejam julgados pelo TPI, inclusive prevendo o uso da força na realização dessa tarefa. $^{14}$

Os Estados Unidos pela primeira vez deixaram de indicar um juiz para compor uma corte mundial. Demonstram novamente sua opção atual por uma linha política egoísta e prepotente, que desrespeita princípios fundamentais do Direito Internacional, como o da solução pacífica dos conflitos, e ignora o papel das Organizações Internacionais como responsáveis pela manutenção da paz e segurança internacionais.

3. A Emenda 45 alterou também o artigo 102 e 105, retirando a competência do STF para a homologação de sentença estrangeira e

\footnotetext{
${ }^{13} \mathrm{O}$ Estatuto de Roma estabelece que os Estados partes têm obrigação de entregar-lhe os indiciados que estejam em seu território, independentemente de serem nacionais ou estrangeiros. No entanto, dispõe em seu artigo 98, 2 que o Tribunal "não dará curso a uma solicitação de entrega em virtude da qual o Estado requerido deva atuar de forma incompatível com as obrigações que the imponham um acordo internacional (...)". Aproveitando essa brecha no tratado e levando em consideração que a maioria dos oficiais que participam de missões da ONU são de nacionalidade norte-americana, o governo de Washington passou a exigir dos países da comunidade internacional que assinassem acordos bilaterais (chamados de acordos sobre o artigo 98) com os EUA, comprometendo-se a não entregar americanos ao TPI. Vários países cederam às pressões e estima-se que atualmente cerca de 50 países já celebraram os acordos bilaterais. Em relação aos países resistentes, os EUA utilizaram uma conhecida tática de intimidação: seu poderio econômico. Assim, a partir de 1/7/2003, programas de assistência militar, que englobam financiamento, educação e treinamento militar, destinados a determinados países estrangeiros, inclusive o Brasil, foram suspensos. Vale lembrar que alguns aliados tradicionais e os membros da OTAN foram isentos de tal represália. Apesar do impacto financeiro ser pequeno, a atitude do governo Bush demonstra sua real intenção de boicotar o TPI e impedir seu completo funcionamento, além de deixar claro sua pretensão de ser, ele próprio e não o TPI, o guardião da justiça mundial.

14 "Lei sobre proteção de oficiais americanos" ("American Servicemembers Protection Act, 2002"), p.ex., que prevê, dentre outros dispositivos, a suspensão de ajuda militar a Estados que são partes do TPI e não assinaram o Acordo Bilateral com os EUA.
}

Revista Brasileira de Direito Internacional, Curitiba, v.8, n.8, jul/dez.2008 
concessão de exequatur às cartas rogatórias. Embora não diga respeito diretamente ao tema dos direitos humanos, atualmente entende-se que a cooperação internacional jurisdicional é um direito da pessoa envolvida num caso judicial conectado a ordenamento jurídico de mais de um país, transformando-se, assim, em dever dos Estados envolvidos. Assim, o artigo 9o da EC 45 revogou a alínea $h$ do inciso I do art. 102 da CF e o artigo 1ํ deixou o artigo 105 da CF com a seguinte redação:

"Art. 105 Compete ao STJ: (...)

i) a homologação de sentenças estrangeiras e a concessão de exequatur às cartas rogatórias;"

É comum os países exigirem um procedimento especial para dar efeito a sentenças proferidas por juiz no estrangeiro e atos processuais por ele solicitados para serem realizados por juiz nacional. No Brasil, coube tradicionalmente ao Supremo Tribunal Federal a tarefa de homologar a sentença estrangeira e conceder exequatur às cartas rogatórias. Através destas, o juiz de uma país solicita (roga) a um juiz de outro país que realize determinados atos. "As decisões interlocutórias (citação, vistoria, oitiva de testemunha) não são homologáveis. Tais atos, contudo, não são indiferentes ao Direito do Brasil, sendo objeto de carta rogatória. ${ }^{15}$,

Já as sentenças estrangeiras necessitam de homologação enquanto "ato que torna a sentença estrangeira exeqüível na ordem jurídica interna. É, portanto, a homologação que vai permitir a execução, em um país, de decisão proveniente de órgão judiciário de outro". ${ }^{16}$

A mudança na Constituição ocasiona a necessidade de mudança no regimento interno do STF, que regulamentava os dois institutos, com sua

${ }^{15}$ DEL'OLMO, Florisbal de Souza. Direito Internacional Privado. Abordagens fundamentais, Legislação, Jurisprudência. São Paulo: Forense, 2003. 5.ed. p. 70

${ }_{16}$ Idem, p. 71. "Recorde-se que a palavra exequator, expressão latina, forma verbal, que significa execute-se, cumpra-se, é empregada no Brasil para admissão de carta rogatória. Muitos autores, mormente de outros países, empregam-na para a aceitação de sentença, o que, em princípio, não ocorre entre os doutrinadores e legisladores brasileiros, que preferem referir-se à homologação ou ao reconhecimento como o caminho para a exeqüibilidade da sentença forasteira. Quatro expressões - homologação, exequator, reconhecimento e delibação, nessa ordem, - são, por vezes, empregadas para indicar a aceitação, pelo sistema jurídico brasileiro, da sentença estrangeira, ressaltando-se ser mais técnico e mais usado o termo homologação. P. 71-72.

Revista Brasileira de Direito Internacional, Curitiba, v.8, n.8, jul/dez.2008 
adequação no regimento do STJ. Esta corte passa agora a ser a instância de delibação, sendo que a instância de execução continua sendo a Justiça Federal, nos termos do artigo 109, X da CF.

Ambos os procedimentos enquadram-se no tema da Cooperação Judiciária Internacional, hoje não mais tratado como um ato de disposição de Estado mas como um direito fundamental da pessoa envolvida em um processo judicial relacionado a mais de um país, respeitando-se, é claro, a ordem pública do país requerido.

O grande crescimento das demandas envolvendo interesses transnacionais - seja no sentido ativo ou passivo - e a correspondente necessidade de produção de atos em um país para cumprimento em outro são tendências resultantes da crescente internacionalização da economia.

Para garantir a rapidez e a eficácia do trânsito de atos processuais e jurisdicionais são necessárias normas especiais, que permitam o cumprimento dessas medidas. Essa obrigação dos Estados resulta de um dever de cooperação mútua para assegurar o pleno funcionamento da Justiça. Ao mesmo tempo, deve-se também assegurar os direitos fundamentais protegidos no âmbito da Constituição e dos Tratados internacionais de direitos humanos. Esses direitos fazem parte de um catálogo dos direitos do cidadão e não mais apenas uma obrigação entre nações soberanas, por força da cortesia internacional. Vislumbra-se uma relação direita entre esses atos processais transfronteiriços e os direitos fundamentais através de processo no qual as garantias de defesa sejam respeitadas. Há uma preocupação do esforço codificador internacional em encontrar soluções uniformes, no plano global - por meio de convenções internacionais, multilaterais ou oriundas de processos de integração.

Quando se analisam as decisões do STF em Cartas Rogatórias (CRs) e Sentenças Estrangeiras (SES), verifica-se a aplicação do princípios constitucionais de proteção da pessoa. ${ }^{17}$

Tal entendimento foi incorporado também pelo STJ.

4. A última alteração constitucional relevante para a questão internacional dos direitos humanos foi a inclusão do inciso $\mathrm{V}$, letra a, no artigo 109, que assim ficou redigido:

"Art. 109 Aos juízes federais compete processar e julgar:

\footnotetext{
${ }^{17}$ ARAUJO, Nadia de. Direito Internacional Privado. Teoria e Prática Brasileira. Rio de Janeiro: Renovar, 2004. 2.ed. p. 248-249.
}

Revista Brasileira de Direito Internacional, Curitiba, v.8, n.8, jul/dez.2008 
$\mathrm{V}-\mathrm{A}$ - as causas relativas a direitos humanos a que se refere o $\S 5^{\circ}$ deste artigo";

"§ $5^{\circ}$ Nas hipóteses de grave violação de direitos humanos, o Procurador-Geral da República, com a finalidade de assegurar o cumprimento de obrigações decorrentes de tratados internacionais de direitos humanos dos quais o Brasil seja parte, poderá suscitar, perante o Superior Tribunal de Justiça, em qualquer fase do inquérito ou processo, incidente de deslocamento de competência para a Justiça Federal."

A Emenda Constitucional 45 criou um novo mecanismo a partir do qual - Procurador Geral da República tem a faculdade de solicitar o desvio da autoridade judiciária sobre determinado caso, do STJ para a Justiça Federal. Isso somente ocorrerá em casos de grave violação de direitos humanos e com o objetivo de garantir a observância de tratados internacionais sobre o tema.

Trata-se de uma exigência antiga da área de direitos humanos, que hoje não se limita ao plano interno mas está intimamente vinculada ao plano internacional em virtude dos inúmeros tratados em negociação ou em vigor, os quais freqüentemente criam mecanismos de monitoramento e implementação de suas cláusulas.

Em diversas situações se verificou a falta de compromisso com o caso por parte da autoridade policial, na fase do inquérito, ou da justiça estadual, durante o processo judicial. A demora injustificada, a denegação da justiça e a desídia ou negligência por parte dos operadores do Direito criaram muitas vezes campo para se acessar mecanismos internacionais de Direitos Humanos. No Brasil, muitos casos foram parar na Comissão Interamericana de Direitos Humanos e depois levados para a Corte Interamericana. Estas, por diversas vezes solicitaram ao país informações sobre a situação em causa ou adoção de determinadas medidas para acabar ou coibir as violações de direitos humanos e não raro a resposta obtida foi neste sentido: a competência para esses casos é dos estados da federação brasileira e a União nada pode fazer.

A nova redação do artigo 109 permitirá uma mudança fundamental diante desse tipo de circunstância, colocando o país definitivamente no rol dos Estados compromissados com a proteção e promoção dos Direitos Humanos. 
Em 1995 a Comissão Interamericana esteve no Brasil para uma missão geral de observação in loco da realidade dos Direitos Humanos e na época já sugeria uma alteração na competência jurisdicional brasileira sobre crimes contra os direitos humanos. CANÇADO TRINDADE explica que a Comissão emitiu um comunicado à imprensa no qual relatou que

(...) havia tomado conhecimento da Lei de Reconhecimento dos Desaparecidos Políticos (recém-aprovada), assim como de projetos de lei pertinentes tais como, inter alia, os relativos à chamada "federalização dos crimes" contra os direitos humanos, à proteção de vítimas e testemunhas, e à transferência ao foro comum dos crimes perpetrados por policiais militares no exercício de suas atividades de ordem pública; recomendou a Comissão que medidas legislativas dessa natureza (e outras medidas administrativas propostas) fossem "adotadas e implementadas no menor prazo possível, a fim de protegerem de forma mais eficaz os direitos e garantias consagrados na Convenção Americana [sobre Direitos Humanos]”, na qual o Brasil é Parte. ${ }^{18}$

Como se pode perceber, muito ainda há que ser feito. Mesmo no que tange ao Incidente de Deslocamento do Competência, muitas questões ainda têm que ser resolvidas: cabe análise pelo STJ do pedido do Procurador-Geral? Quem o analisará, a Terceira Turma? O STJ poderá denegar a solicitação? Em caso afirmativo, caberá Recurso Extraordinário para o STF? O deslocamento da competência poderá ocorrer depois de transitado em julgado (na fase da execução da pena, por exemplo?) Se o agente tiver foro especial, a competência será deslocada para o Tribunal Regional Federal correspondente? Se se tratar de crime doloso contra a vida, a competência desloca-se do Tribunal do Júri da Justiça Estadual para o da Justiça Federal.? Parece-nos que as respostas tendem a ser afirmativas, entretanto, somente a prática diária resolverá os questionamentos. No momento, pode-se dizer que um importante primeiro passo foi dado através da recepção, pela Constituição, dos anseios da comunidade internacional que se preocupa com a proteção dos Direitos Humanos. Resta, entretanto, a efetivação desta mudanças constitucional pois

\footnotetext{
${ }^{18}$ CANÇADO TRINDADE, Antonio Augusto. A proteção internacional dos direitos humanos e o Brasil (1948-1997): as primeiras cinco décadas. Brasília: Editora Universidade de Brasília. 2.ed, 2000. p. 95-96.
}

Revista Brasileira de Direito Internacional, Curitiba, v.8, n.8, jul/dez.2008 
no caso do assassinato da irmã Dorothy, o incidente de deslocamento foi solicitado mas não foi deferido.

Diante de todo o exposto, fica claro que o Direito Internacional e o Direito Constitucional são parceiros na promoção dos Direitos Humanos, estes considerados em suas três dimensões: direito humanos propriamente ditos, direito dos refugiados e direito humanitário.

Direito Internacional e Direito Constitucional, em sintonia, atuam como instrumentos para a exteriorização do elenco de direitos, garantias e deveres que devem ser respeitados para se realizar a concreta efetivação do princípio da dignidade da pessoa humana.

\section{REFERÊNCIAS}

ARAUJO, Nadia de. Direito Internacional Privado. Teoria e Prática Brasileira. Rio de Janeiro: Renovar, 2004. 2.ed.

BONAVIDES, Paulo. Teoria do Estado. São Paulo: Malheiros Editores, 3ed. p.232

CLÈVE, Clemerson Merlin. Atividade Legislativa do Poder Executivo no Estado Contemporâneio e na Constituição de 1988. São Paulo: Editora Revista dos Tribunais, 1993. p. 38.

DEL'OLMO, Florisbal de Souza. Direito Internacional Privado. Abordagens fundamentais, Legislação, Jurisprudência. São Paulo: Forense, 2003. 5.ed.

PIOVESAN, Flavia. Direitos humanos e o Direito Constitucional Internacional. São Paulo: Max Limonad, 2000. 4.ed.

ROCHA, Cármen Lúcia Antunes. Princípios Constitucionais dos Servidores Públicos. São Paulo: Saraiva,1991. p. 48.

TRINDADE, Antonio Augusto Cançado. (Ed) A Incorporação das Normas Internacionais de Proteção dos Direitos Humanos no Direito Brasileiro. San Jose, Costa Rica: Co-edição: IIDH, ACNUR, CICV, CUE, 1996.

TRINDADE, Antonio Augusto Cançado. A proteção internacional dos direitos humanos e o Brasil (1948-1997): as primeiras cinco décadas. Brasília: Editora Universidade de Brasília. 2.ed, 2000. 